\title{
PrecarizaÇão do trabalho e PROCESSO PRODUTIVO DO CUIDADO
}

\author{
Helaynne Ximenes Faria ${ }^{1}$ \\ e Maristela Dalbello-Araujo ${ }^{2}$
}

\begin{abstract}
Resumo
Apesar de suas especificidades, o setor saúde também sofre influências neoliberais que provocam efeitos no mundo do trabalho. Este artigo retrata as conseqüências negativas da precarização sobre o processo de produção de cuidado em saúde, a partir da análise de uma Unidade de Saúde cuja maioria da equipe é terceirizada. Por meio dos relatos obtidos, pode-se verificar o sentimento de desvalorização expresso pelos trabalhadores, assim como a constatação de que a assistência à saúde da população fica comprometida devido ao ambiente tenso, marcado pela instabilidade do emprego, insatisfação e adoecimento dos trabalhadores. Sugerese o investimento em políticas de enfrentamento da precarização no SUS, visto que ela coloca em risco as diretrizes e princípios desta política pública.
\end{abstract}

Palavras-chave: Política de saúde. Força de trabalho. Precarização. Processo de trabalho.

\section{Precariousness of WORK AND CARE PRODUCTIVE PROCESS}

\section{Abstract}

Despite its specificities, the health area is also under neoliberal influences which can affect the work field. This article points out the negative consequences of

\footnotetext{
${ }^{1}$ Mestre em Psicologia Institucional pela Universidade Federal do Espírito. helaynneximenes@ click21.com.br

${ }^{2}$ Professora Doutora do Departamento de Psicologia e do Programa de Pós-Graduação em Saúde Coletiva da Universidade Federal do Espírito Santo. dalbello@intervip.com.br
} 
precariousness in the health care production process, based on the analysis of the work process of a Health Unit, where most of the staff is outsourced. Accounts given by workers express their sentiment of devaluation as well as the statement that the health care offered to the population is clearly compromised due to the stressful environment, where workers lack stability, feel dissatisfied and frequently get sick. What is suggested is the investment on policies to deal with the precariousness of SUS, since it puts the guidelines and principles of this public policy at risk.

Keywords: Health policy. Work force. Precariousness. Process of work.

\section{INTRODUÇÃO}

E

ste artigo se origina de pesquisa realizada no serviço "Estratégia de Saúde da Família (ESF)", do Sistema Único de Saúde (SUS), no estado do Espírito Santo. A ESF é uma das propostas de organização dos serviços de Atenção Primária à Saúde (APS) e tem sido considerada pelo Ministério da Saúde (MS) como um dos grandes trunfos para mudanças e para a reorganização da assistência (BRASIL, 2006a).

Reconhecido como um importante marco nas políticas públicas, o SUS é organizado em um complexo sistema de serviços e ações que abrange a responsabilidade da União, dos Estados e dos Municípios para o bem-estar da população. As ações devem se basear nos princípios de universalidade, integralidade e equidade, garantindo o direito de acesso de todo cidadão aos serviços necessários à sua saúde. Com origem nos movimentos de democratização do país, cujo principal expoente é a Reforma Sanitária (ARRETCHE, 2005), o SUS postula a abertura para a participação social nas decisões da gestão, na formulação e execução das políticas e na fiscalização dos gastos. 0 princípio da participação social é uma conquista e retrata o caráter democrático que o SUS preconiza, ao possibilitar que gestores, trabalhadores e usuários decidam em conjunto os rumos da política de saúde.

0 SUS possui uma rede hierarquizada de serviços, caracterizados como Atenção Primária, Secundária e Terciária. A Atenção Primária deve, de acordo com a política ministerial (BRASIL, 2006a), abranger os serviços e ações que objetivam a resolução da maioria das questões de saúde da população. Tais ações e serviços possuem caráter individual e coletivo referentes à promoção e à proteção da saúde, à prevenção de agravos, ao diagnóstico, ao tratamento, à reabilitação e manutenção da saúde.

Dentro dos serviços de Atenção Primária, atualmente existentes, encontram-se as Unidades de Saúde da Família (USF) que são serviços orientados 
para a reorganização do processo de trabalho em saúde. Na busca por superar um modelo pautado na cura de doenças e no ambiente hospitalar, a ESF surge como forma de modificar a assistência, centrando-se na família, na comunidade e no cuidado. 0 foco do trabalho está na territorialização e na adscrição de clientela, 0 que significa que uma equipe de trabalhadores, composta minimamente por um médico, um enfermeiro, um auxiliar de enfermagem e de quatro a seis agentes comunitários de saúde, é responsável por cadastrar e acompanhar cerca de 600 a 1000 famílias (FRANCO; MERHY, 2006). Cabe a esta equipe desenvolver visitas domiciliares, ações programáticas e atendimentos ambulatoriais, visando prevenir agravos, por meio de atividades de vigilância à saúde. 0 interesse é que a equipe de saúde da família seja "a referência" para as famílias de seu território, atuando de forma a fortalecer 0 vínculo com os usuários e estimular a co-participação no processo de produção do cuidado.

Neste sentido, a ESF tem sido valorizada pelo seu potencial gerador de mudanças na lógica de se prestar assistência à saúde. A ela são atribuídas características inovadoras e reestruturadoras capazes de romper com visões fragmentadas do usuário, que passa a ser visto de maneira mais ampla, de acordo com seu ambiente de vida. Ou seja, busca substituir o modelo assistencial em saúde, transformando práticas antes centralizadas no atendimento médico, medicamentoso, curativo e individual, em um modelo coletivo voltado para 0 atendimento multi e interprofissional, centrado na família e na comunidade (COSTA et al., 2009).

Devido a esta valorização, diversas análises têm sido realizadas em torno da ESF, sobretudo ao abordarem o processo de trabalho como temática pertinente, tendo interesse na dimensão relacional e micropolítica da produção do cuidado (FRANCO; MERHY, 2006; FRANCO; ANDRADE; FERREIRA, 2009). 0 foco está no trabalho, ação entendida como central na vida humana, bem como na importância de avaliar o processo de trabalho em saúde como algo capaz de produzir procedimentos especializados e atos cuidadores, quanto competente para erigir sujeitos protagonistas na construção de um sistema de saúde democrático e justo (FARIA; DALBELLO-ARAÚJO, 2010).

Ressalta-se que apesar do grande incentivo em torno da proposta saúde da família e da rápida expansão ocorrida no número de equipes existentes no país, há questões importantes que impedem que os seus objetivos sejam atingidos. Uma dessas questões diz respeito à organização do processo de trabalho. Percebese a insistência do modelo tradicional biomédico entre as práticas de saúde que 
são desenvolvidas diariamente nos serviços (FRANCO; MERHY, 2006; COSTA et al., 2009). Outro aspecto dificultador são as modalidades de contratação dos trabalhadores da ESF. Muitos deles possuem vínculos contratuais considerados frágeis (ESPINDULA, 2008), demonstrando que o trabalho em saúde é também influenciado pelas artimanhas de controle do capital para manter sua hegemonia, mesmo possuindo características próprias que o diferem dos demais campos produtivos. Tais especificidades dizem respeito ao fato do trabalho em saúde lidar com vidas e de ser altamente dependente das interseções (MERHY, 2002) e dos encontros realizados entre os sujeitos (FARIA; DALBELLO-ARAÚJ0, 2010; FRANCO; ANDRADE; FERREIRA, 2009).

Mudanças no mundo do trabalho são influenciadas pelos avanços tecnológicos e pelas novas necessidades do capital para manter sua força. Tentativas de sistematização, como as baseadas nos pressupostos tayloristas/fordistas foram inicialmente operacionalizadas nos ambientes das fábricas, mas também se estenderam a outros ramos, como o de serviços (BRAVERMAN, 1987). Entretanto, estas tentativas mostraram fragilidade para sozinhas se manterem frente às novas exigências do mercado, havendo a necessidade de reorganização das relações trabalhistas via flexibilização implementada por novos modelos como o toyotista (DEJOURS, 1993). Discute-se que esta nova época caracterizada por acumulação flexível, neoliberalismo e reestruturação produtiva gerou efeitos nefastos como desemprego em massa, precarização do trabalho, exclusão e degradação da relação do homem com a natureza, em um contexto obsessivamente voltado para a produção de mercadorias (ANTUNES, 2007). 0 trabalho passa a ser desregulamentado e flexibilizado para dotar o capital de ferramentas necessárias a sua adaptação às crises. Este movimento acaba por afetar direitos trabalhistas e tornar as relações transitórias. Também não se limitou a um só ramo produtivo, afetando também serviços públicos, como os do SUS, minando a potência desta nossa política social.

Apesar de ter sido constituído em meio aos movimentos de democratização da década de 1970 (ARRETCHE, 2005), o SUS teve seu início tumultuado ao se deparar com a orientação neoliberal, ocorrida nos anos de 1990, incentivada pelos mecanismos internacionais de financiamento aos países em desenvolvimento, dentre eles o Brasil. Abertura comercial, privatização e estabilização econômica formam as bases das intervenções neoliberais (BOSCH; LIMA apud ESPINDULA, 2008). Estas intervenções afetam o mundo do trabalho e das políticas sociais como é o caso do SUS. A orientação neoliberal incentiva um movimento em favor do comércio, com ações fiscais, linhas de crédito e liberação de preços. Ela se 
destaca pela sucessiva redução do Estado quanto às políticas sociais, apresentando propostas de privatizações e cortes nos gastos públicos, aspectos contrastantes dos propostos pelos ideários do SUS e da Reforma Sanitária.

Neste contexto, a efetivação da política de saúde encontra dificuldades como a questão do financiamento. Entretanto, apesar do foco ser mais reconhecidamente econômico, há esforços do pensamento neoliberal de trabalhar de forma ampla, inclusive atuando na produção subjetiva. A ideologia neoliberal ressalta a importância do indivíduo e a sua livre escolha de bens e serviços a serem consumidos. Assim, os cidadãos não são reconhecidos como sujeitos de direito, mas como consumidores e como tal devem pagar pelos serviços que desejam e necessitam. 0 ideário neoliberal afirma que os bens e serviços como saúde, educação e seguridade social seriam responsabilidade dos indivíduos. A oferta de tais serviços seria regulada pelo livre mercado, devendo o Estado se limitar a atuar somente frente a carências extremas. Ou seja, percebe-se que neste contexto o direito à saúde encara grande ameaça, uma vez que a responsabilidade do ônus do Estado é jogada sobre as políticas sociais, dentre elas a saúde (BRASIL, 2006b).

Assim, não há como deixar de considerar que dentro deste contexto marcado pelo individualismo, consumismo e competitividade, no qual cada um deve arcar consigo, a idéia de que SUS é uma política voltada para pobres e incapazes permeia o imaginário dos sujeitos, despotencializando grande parte das conquistas estabelecidas pelo processo da Reforma Sanitária.

Nogueira, Baraldi e Rodrigues (2004) apontam que, entre as décadas de 1980 e 1990, houve uma reorganização estrutural pautada nos princípios neoliberais com conseqüências negativas para as condições de vida e de trabalho dos assalariados. Trata-se de alterações nos processos produtivos, nos vínculos contratuais e nas formas de remuneração dos trabalhadores, afetando direitos trabalhistas conquistados. Neste contexto, observam-se mudanças voltadas para a desregulamentação e a flexibilização do processo de trabalho, gerando precarização. Estas alterações atingiram também os setores públicos e os serviços de saúde numa maré de ações para enxugar os gastos e propiciar maior eficiência do Estado.

No setor público a reforma estrutural, pautada nos princípios neoliberais, ocorreu a partir do governo Fernando Collor de Melo que apontou justificativas no excesso de funcionários e nos salários abusivos de certa elite (os marajás). Ali se iniciou um processo de planos de demissão de pessoal e medidas de diminuição 
do tamanho da máquina estatal (NOGUEIRA, 2006). As medidas seguiram nos governos seguintes, culminando com uma política de contenção financeira e uma legislação disciplinadora em torno dos gastos com pessoal. Uma das preocupações do governo foi diminuir o número de servidores públicos em regime estatutário. Assim, há a abertura para um movimento de terceirizações nos serviços públicos por prestadores de serviço ou pela contratação de pessoal por tempo determinado. Neste contexto, observam-se também transformações de entidades públicas em Organizações Sociais (OS) de direito privado, além da quebra da estabilidade do emprego dos servidores públicos e o fim do regime jurídico único de trabalho, fatos que acarretaram em diversos tipos de vínculos de contratos de trabalho, seja por cooperativas, fundações privadas e organizações não governamentais (ONG) (ESPINDULA, 2008).

Quanto aos serviços de saúde, percebe-se que desde os anos de 1990 ocorreram mudanças no parque sanitário brasileiro, devido à grande expansão de empregos no setor saúde sob a responsabilidade dos municípios (MACHADO et al., 2005). Pelas propostas do SUS, houve uma reformulação do modelo de atenção, que a passa a assumir uma forma regionalizada de organização pautada na descentralização. Deste modo, os municípios se tornaram os maiores responsáveis pela contratação de trabalhadores do SUS, mas encontraram dificuldades em se organizar diante da Lei de Responsabilidade Fiscal (LRF), sancionada em 2000 e que reflete 0 ideário neoliberal. A LRF define que as despesas com pessoal não podem ultrapassar $50 \%$ da receita dos estados e municípios e $60 \%$ no que se refere ao nível Federal (BRASIL, 2000). Tal legislação parece limitar a autonomia do setor público para contratações de pessoal (PIERANTONI; VARELLA; FRANÇA, 2004).

Como efeito deste processo, muitos municípios frente à LRF e sem orientação a respeito de como proceder com as novas exigências ministeriais, além de sofrer com instabilidades administrativas e orçamentárias, acabaram optando por formas de contratação via parcerias com 0NGs, Organizações Sociais de Interesse Público (OSCIPS), OS e cooperativas. Desde então, surgiram problemas associados à precarização dos vínculos de trabalho (BRASIL, 2009a).

Neste contexto, Machado et al. (2005) consideram a década de 1990 como perdida para os recursos humanos, cujo contexto é marcado pelo abandono das propostas de planos de carreira profissional, pela precarização do trabalho no SUS e pela desmobilização do movimento sindical. Araújo et al. (2006) relatam que houve um uso indiscriminado, e muita das vezes em discordância legal, das contratações terceirizadas em decorrência da conjuntura econômica e política, 
que negligenciou a gestão de recursos humanos. Assim, verifica-se um descuido com os trabalhadores, uma vez que são peças chave para a consolidação do SUS.

0 Ministério da Saúde reconhece que a adoção de uma política de precarização das relações de trabalho, mediante determinadas formas de contratação, implica na fragilização da qualidade de comprometimento e nos serviços prestados. Há o empenho em desenvolver ações de valorização do trabalhador, como o Programa Nacional de Desprecarização do Trabalho do SUS (BRASIL, 2006c), cujo principal objetivo é formular políticas de eliminação do trabalho precário. Durante o governo do presidente Luiz Inácio Lula da Silva foi criada a Secretaria de Gestão do Trabalho e da Educação na Saúde, que tem como premissa lidar especialmente com a gestão dos recursos humanos em saúde (MACHADO et al., 2005). Além disso, destaca-se a Política Nacional de Humanização (PNH) do Ministério da Saúde (BRASIL, 2009b), que tem como uma de suas diretrizes a valorização do trabalho e do trabalhador do SUS, compreendendo o trabalhador como um importante sujeito no processo produtivo.

No entanto, apesar de tais movimentos, ainda há um grande contingente de trabalhadores em situação precarizada, acarretando em efeitos negativos como apontam Machado et al. (2005) a respeito do estabelecimento de ambientes pouco saudáveis e que implicam em consequiências para a assistência prestada aos usuários. Com estas questões, este estudo tem por objetivo analisar os efeitos das formas de contratação no processo de trabalho de uma USF do Espírito Santo, especialmente no que se refere às interferências na produção do cuidado.

\section{Metodologia}

Durante oito meses de 2009, foi realizada uma pesquisa com abordagem qualitativa em uma USF ${ }^{3}$. Adotou-se postura cartográfica no estudo (ROLNIK, 2006), considerando a Cartografia como um viés analítico no qual o pesquisador se baseia em um roteiro de preocupações que corresponde a seus objetivos, mas mantém sua atenção flutuante (KASTRUP, 2007) de forma a captar a riqueza do que é produzido no território pesquisado e aos efeitos dos processos em jogo.

Realizamos duas entrevistas semi-estruturadas com pessoas que ocupam cargos de gestão na Secretaria Municipal de Saúde de um município do Espírito Santo, uma delas coordenadora da ESF, e mais 14 entrevistas com os trabalhadores

\footnotetext{
${ }^{3} 0$ projeto da pesquisa obteve autorização do Comitê de Ética e Pesquisa do Centro de Ciências da Saúde da Universidade Federal do Espírito Santo.
} 
da USF, incluindo a gerente da unidade. Também foram realizadas duas sessões de entrevista coletiva com a participação de 19 trabalhadores da USF. Em todo o processo procurou-se incluir trabalhadores de todos os níveis de escolaridade e formação, assim como de todos os setores da USF. Além das entrevistas, também foram realizadas observações do cotidiano e conversas informais com trabalhadores e usuários da USF.

Todo o material foi gravado e transcrito para posterior análise, destacandose os aspectos que descreviam o processo de trabalho, as questões envolvendo as modalidades de contratação e as maneiras de cuidado prestado aos usuários.

\section{Resultados E Discussões}

Correspondem ao total de trabalhadores da USF sessenta profissionais, incluindo profissionais de diferentes categorias: médicos, enfermeiros, odontólogos, técnicos e auxiliares de enfermagem, técnicos de higiene dentária, agentes comunitários de saúde, atendente de consultório dentário, vigilantes, pessoal da limpeza, gerente e assistente social. Deste quantitativo, dez são concursados e efetivos e os restantes possuem vínculos terceirizados, como o pessoal da vigilância e limpeza e toda a Equipe de ESF, que é contratada por uma OSCIP.

A ESF funciona no município desde 2003. Sabe-se que o último concurso público foi realizado em 2005 e não incluiu cargos relativos à ESF. As contratações para a ESF são efetuadas via contratos terceirizados. De acordo com os relatos obtidos na Secretaria de Saúde, o município adota a terceirização como forma de contratar as equipes de PSF para contornar as dificuldades existentes. São citados fatores como baixo orçamento e escassez de recursos humanos, além de questões como aprovação de leis na Câmara Municipal para a criação de cargos para a ESF.

0 expediente utilizado pela Secretaria de Saúde deste município é semelhante ao que ocorre em várias regiões do país: utilizar contratações temporárias para instalar as equipes de ESF (COSTA et al., 2009; ESPINDULA, 2008; GONÇALVES et al. 2009; FLEGELER et al., 2008, 2010; LOURENÇO et al. 2009). Percebe-se, neste contexto, os efeitos do processo de reforma neoliberal do Estado e da flexibilização da força de trabalho, tal qual constatado em pesquisas na área (NOGUEIRA; BARALDI; RODRIGUES, 2004). 0 serviço público cada vez mais assume um papel de regulador das ações, delegando a função da contratação de pessoal para outras entidades (DAL POZ, 2002). Multiplicam-se, desta forma, os mecanismos de terceirização de serviços através de variadas modalidades (cooperativas, ONGS, OSCIPS, etc.) que implicam em verdadeiros entraves para 
que o ESF atinja seus objetivos. Para além das questões legais que esta prática de terceirização implica, já que para os juristas ela é ilegal e ilegítima (DANTAS, 2007; NOGUEIRA, 2006), estas modalidades de contratação são precárias, pois colocam o trabalhador numa situação delicada, uma vez que algumas não garantem benefícios assistenciais e demais direitos trabalhistas. Além disso, revelam-se como um empecilho para a efetivação da ESF, visto que esta preconiza a continuidade do vínculo do profissional com a comunidade, o que é improvável de ocorrer com a verificada rotatividade dos profissionais ocasionada pela instabilidade do vínculo trabalhista (COSTA et al., 2009).

Trabalho precário refere-se à desproteção social; isto é, situações em que os trabalhadores não têm direitos e benefícios assegurados pelas legislações trabalhistas, como licença maternidade, férias anuais, décimo terceiro salário, aposentadoria e outros. Araújo et al. (2006) incluem nesta definição elementos como baixos vencimentos e inadequadas condições de trabalho na delimitação do que seja trabalho precário. Também podem ser considerados trabalhos precários aqueles com tempo determinado, e a precariedade, neste caso, refere-se também ao sentimento de instabilidade que causa ao trabalhador (NOGUEIRA; BARALDI; RODRIGUES, 2004). Um dos relatos é exemplar desta condição.

A gente às vezes fica pensando "Até a onde eu posso ir?". Ás vezes tem planos para o futuro e tal, mas eu não sei se eu vou poder. Porque não sei se eu vou estar trabalhando amanhã. Isso é uma das grandes dificuldades que a gente tem (trabalhador).

Neste sentido, a precarização sob a forma de sensação de instabilidade do trabalhador demonstrou sua força no período em que foi realizado o estudo na USF. A pesquisa se deu simultaneamente às mudanças na administração local. Após a realização das últimas eleições municipais, iniciou-se um novo comando administrativo, encerrando uma gestão anterior que havia governado por oito anos (2001-2008). Com a troca do prefeito, ocorreu também a do secretário de saúde, das coordenações da Secretaria de Saúde e das unidades de saúde. Além disso, expirou o prazo dos contratos com a empresa encarregada da terceirização dos trabalhadores da ESF e novos trâmites foram necessários. Este momento foi caracterizado por turbulências no processo de trabalho, principalmente pela sensação de desassossego que os trabalhadores relataram frente à possibilidade de quebra de vínculos contratuais. 
Segundo os depoimentos, a USF já passava por dificuldades de pessoal antes mesmo da mudança da gestão, especialmente no que diz respeito à falta de agentes comunitários de saúde e médicos. Entretanto, a situação se agravou com estas mudanças. Com a nova gestão, comandada por um partido diferente da anterior, houve a troca de chefias e toda equipe demonstrou apreensão pelas mudanças e a renovação dos contratos de trabalho. Este sentimento foi relatado principalmente quando parte da equipe se preparava para receber 0 aviso prévio.

Ninguém sabe se vai ficar, se vão trocar de equipe, se o contrato será renovado, se o trabalho vai continuar, se a ESF vai se manter (trabalhadora).

Embora os profissionais que trabalham sob a ESF do município recebam proventos salariais maiores do que os demais trabalhadores das unidades tradicionais, em função dos incentivos ministeriais para o desenvolvimento da proposta saúde da família, verifica-se um quadro psicossocial crítico dada as condições de estresse a que estão submetidos, especialmente considerando as turbulências do momento descrito. Em geral as falas dos trabalhadores indicam 0 iminente fim do contrato de trabalho como a principal fonte de tensão e refletem sensações de estar impotentes e a mercê da situação vivenciada. Este sentimento foi constatado em outras pesquisas, como a de Lourenço et al. (2009), que retrataram a precariedade do contrato de trabalho de cirurgiões dentistas em Minas Gerais. 0 fato de não ter controle sobre a manutenção do vínculo também provoca sensações de desvalorização.

A gente faz um trabalho desses e aí de repente o pessoal botando o nosso trabalho no menor... Eu brinco assim que nosso trabalho está valendo menos que esse lixo. Entendeu? Tipo assim: não tem ainda médico pra colocar, mas se na semana que vem tiver não importa se você é boa ou se não é, você vai parar na rua (trabalhadora).

0 estresse, a desvalorização e o sentimento de desmotivação provocam efeitos negativos na saúde destes profissionais. Frente ao vivenciado pela equipe, mesmo aqueles que não receberam aviso prévio ou aqueles cujos contratos são efetivos relataram angustia e alguns manifestaram adoecimento.

Semana passada eu não fiquei legal, passei mal. To com náuseas, tava assim... quase que esses dias eu precisei tomar um antidepressivo, porque senão... (trabalhadora).

A fala desta trabalhadora corrobora com o que definem Machado et al. (2005) como sendo indicativo da precarização, uma vez que ambiente tenso e pouco 
saudável implica em condições inadequadas de trabalho e geram adoecimento e sofrimento configurando um quadro de risco ao equilíbrio psicossocial. Neste contexto a situação acaba por se agravar com pedidos de afastamento ou mesmo de demissão, fragilizando ainda mais a equipe. Mesmo após a renovação dos contratos de alguns trabalhadores e com a chegada de novos contratados, a equipe ainda possuía carências de profissionais, principalmente médicos. Insatisfeitos, estressados, adoecidos e com dificuldades em manter o trabalho, a equipe também relata os efeitos danosos no que diz respeito à produção do cuidado prestado a comunidade.

E eu fico refém de uma situação, que preciso pedir um favor pra fulano ou pra ciclano. E está muito difícil [...] Ou a gente resolve ou a gente resolve. Ou a gente manda ele [o usuário] embora pra casa pra morrer. [...] É complicado? É muito (trabalhadora).

0 sentimento de insatisfação não se refere apenas ao temor pela perda do emprego, mas também ao modo verticalizado com que as decisões são impostas na USF. Apesar de um dos princípios do SUS preconizar a participação popular, e de um dos aspectos da humanização dos serviços ser a co-participação dos sujeitos no processo decisório, verifica-se que muito das ações são determinadas de maneira impositiva, sem o tempo hábil para o planejamento adequado que possa possibilitar melhor efetividade e eficiência no que se refere às necessidades de saúde da comunidade.

0 planejamento é feito mesmo de cima pra baixo.[...] Mas aqui trabalha muito com cumprir metas, entendeu? Tem que cumprir meta. (trabalhadora).

Os pressupostos da ESF indicam a co-participação dos sujeitos, a motivação, a responsabilização e a vinculação com o usuário como elementos imprescindíveis para a produção do cuidado (BRASIL, 2006a). Indispensáveis também para a plena implementação da atual política de saúde. Consideram que, além dos aspectos provenientes dos avanços tecnológicos, o trabalhador é um elemento essencial para a produção da saúde, preconizam que esta produção ocorre nos relacionamentos que se estabelecem entre estes e os usuários (MERHY, 2002). Por isso, há de se ressaltar que a assistência prestada pela equipe à comunidade sobre sua responsabilidade resulta de em um ambiente onde estão presentes a dificuldade de participação social, falta de recursos pessoais e materiais e precárias condições de trabalho e contratação. 


\section{Considerações FinaIS}

0 estudo constata os efeitos negativos advindos da escolha adotada pelo municííio para a contratação dos trabalhadores da ESF, especialmente em um momento de mudança na gestão administrativa e proximidade do término dos contratos com as empresas responsáveis pela terceirização dos recursos humanos do setor saúde. Ressalta que as reformas neoliberais ocorridas nos anos 1990, ainda hoje demonstram sua força no que se refere à onda de privatizações, ajustes ficais, terceirização da mão-de-obra. Todas estas medidas provocam efeitos negativos aos trabalhadores e às políticas sociais, como verificados no caso da USF analisada.

Assim, este artigo retrata a precarização do trabalho a que estão submetidos os trabalhadores do SUS. Imersos em um ambiente de instabilidade e vivenciando cotidianamente sentimentos de impotência, desvalorização, angústia, sofrimento e tensão frente à possibilidade de demissão e suas consequiências. Estas dizem respeito tanto ao fim da fonte de renda, quanto ao desperdício de energia e afetos postos a serviço da construção de um projeto coletivo, como é a ESF.

Embora a proposta da ESF possa ser vista como positiva, sobretudo porque valoriza o vínculo com a comunidade e reorienta o foco da atenção no cuidado, no relacionamento e na família, o estudo aponta que ela pode não se efetivar, dadas as condições de trabalho vivenciadas por grande parte dos trabalhadores, especialmente aqueles com vínculos contratuais precários. Nesse sentido, chama a atenção para a necessidade de melhor considerar os trabalhadores que dão corpo às políticas sociais. Eles, juntamente com os usuários, configuram-se como pólos produtivos da saúde e, portanto, requerem mais e melhores estudos e ações enérgicas no sentido de evitar a precarização e a desvalorização da força de trabalho, a energia viva do sistema de saúde.

Apesar do movimento que visa a desprecarização do trabalho no SUS, oriundo do Ministério da Saúde, ainda há muito a ser feito no que tange aos municípios, principal empregador quando se trata de atenção primária à saúde, pois o sentimento de instabilidade provocado no trabalhador a cada nova gestão se revela como um dos entraves para a consolidação dos vínculos entre profissionais e comunidade e para a operacionalizaçã̃o dos princípios constitucionais do setor saúde.

Negligenciar as condições nas quais ocorre o processo de trabalho em saúde é um risco. Como relatado, o contexto vivenciado pelos trabalhadores estudados e, certamente compartilhado por muitos outros, em diversos municípios do país, provoca efeitos negativos às condições de vida dos trabalhadores e usuários, especialmente considerando o adoecimento, a desmotivação e as dificuldades em 
produzir ações cuidadoras em um contexto como este. Trata-se, portanto, de um aspecto que merece maior atenção nos estudos em Saúde Coletiva e em Ciências Sociais.

Análises multicêntricas sobre a temática poderão confirmar a premissa de que manter um ambiente precarizado ameaça as propostas inovadoras da atenção primária e da saúde da família, além de comprometer a efetivação do SUS. Isto porque reflete nos sujeitos um efeito despotencializador que pode implicar em conseqüências negativas, minando a força do movimento social que culminou na atual política de saúde e colocando em xeque tudo o que foi conquistado até então pelo processo político da Reforma Sanitária.

\section{REFERÊNCIAS}

ANTUNES, Ricardo. Adeus ao trabalho? Ensaios sobre as metamorfoses e a centralidade do mundo do trabalho. 12. ed. São Paulo: Cortez, 2007.

ARAÚJO, Lídice Maria et al. Para subsidiar a discussão sobre a desprecarização do trabalho no SUS. Cadernos RH Saúde, Brasília, v. 3, n. 1, mar. 2006.

ARRETCHE, Marta. A política da política de saúde no Brasil. In: LIMA, Nisia Trindade et al. (Org.). Saúde e democracia: história e perspectivas do SUS. Rio de Janeiro: Fiocruz, 2005.

BRASIL. Lei complementar $n^{0}$. 101 de 4 de maio de 2000. Estabelece as normas de finanças públicas voltadas para a responsabilidade na gestão fiscal e dá outras providencias. Diário Oficial [da] República Federativa do Brasil. Brasília, 5 maio 2000. Disponível em: < http://www.planalto.gov.br/CCIVIL/Leis/LCP/Lcp101. htm>. Acesso em: 10 out. 2009.

Portaria $n^{\circ}$. 648, de 28 de março de 2006. Aprova a Política Nacional de Atenção Básica, estabelecendo a revisão de diretrizes e normas para a organização da Atenção Básica para o Programa Saúde da Família (PSF) e 0 Programa Agentes Comunitários de Saúde (PACS). Brasília, 2006a. Disponível em: $<$ http://dtr2004.saude.gov.br/dab/docs/legislacao/portaria_648_28_03_2006. pdf >. Acesso em: 21 nov. 2009.

. Ministério da Saúde. Secretaria de Gestão Estratégica e Participativa. A construção do SUS: histórias da Reforma Sanitária e do Processo Participativo. Brasília: Ministério da Saúde, 2006b.

. Ministério da Saúde. Secretaria de Gestão do Trabalho e da Educação na Saúde. Departamento de Gestão e da Regulação do Trabalho em Saúde. Programa 
Nacional de Desprecarização do Trabalho no SUS. Desprecarização do trabalho no SUS: perguntas e respostas. Brasília: Ministério da Saúde, 2006c.

. Ministério da Saúde. Desprecarização do trabalho no SUS. Disponível

em: <http://portal.saude.gov.br/portal/saude/profissional/area.cfm?id_ area $=1285>$. Acesso em: 25 out. 2009a.

. Ministério da Saúde. Secretaria de Atenção à Saúde. Política Nacional de Humanização da Atenção e Gestão do SUS: Trabalho e redes de saúde. Brasília: Ministério da Saúde, 2009b.

BRAVERMAN, Harry. Trabalho e capital monopolista: a degradação do trabalho no século XX. Rio de Janeiro: Guanabara, 1987.

COSTA, Glauce Dias da et al. Saúde da família: desafios no processo de reorientação do modelo assistencial. Revista Brasileira de Enfermagem, Brasília, v. 62, n. 1, p. 113-118, jan. 2009.

DAL POZ, Mario Roberto. Cambios en la contratación de recursos humanos: el caso del Programa de Salud de la Familia en Brasil. Gaceta Sanitária, Barcelona, v. 16, n. 1, p. 82-88, fev. 2002.

DANTAS, Adriano Mesquita. A terceirização do programa saúde da família: prática ilegal. Jus Navigandi, Teresina, ano 11, n. 1399, maio 2007. Disponível em: <http://jus2.uol.com.br/doutrina/texto.asp?id=9825>. Acesso em: 17 nov. 2009.

DEJOURS, Christophe. Inteligência operária e organização do trabalho. In: HIRATA, Helena. (Org.). Sobre o "modelo" japonês. São Paulo: Ed. Universidade de São Paulo, 1993.

ESPINDULA, Karina Delaprani. Trabalhadores da saúde no SUS: vínculos frágeis - implicações complexas. 2008. Dissertação (Mestrado em Saúde Coletiva) - Universidade Federal do Espírito Santo, Vitória.

FARIA, Helaynne Ximenes; DALBELLO-ARAUJO, Maristela. Uma perspectiva de análise sobre o processo de trabalho em saúde: produção do cuidado e produção de sujeitos. Saúde e Sociedade, São Paulo, v. 19, n. 2, p. 429-439, jun. 2010.

FLEGELE; Débora dos Santos et al. 0 trabalho dos profissionais de saúde na estratégia saúde da família: relações complexas e laços institucionais frágeis. UFES Revista de Odontologia, Vitória, v. 10, n. 4, p. 17-23, out. 2008.

. Trabalhadores de saúde e os dilemas das relações de trabalho na estratégia saúde da família. Revista Brasileira de Pesquisa em Saúde, Vitória, v. 12 , n. 2, p. 5-11, 2010. 
FRANCO, Túlio Batista; MERHY, Emerson Elias. Programa de Saúde da Família - PSF. Contradições de um programa destinado à mudança do modelo tecnoassistencial. In: MERHY, Emerson Elias et al. O trabalho em saúde: olhando e experienciando o SUS no cotidiano. São Paulo: Hucitec, 2006.

FRANCO, Túlio Batista; ANDRADE, Cristina Setenta; FERREIRA, Vitória Solange Coelho. (Org.). A produção subjetiva do cuidado: cartografias da estratégia de saúde da família. São Paulo: Hucitec, 2009.

GONÇALVES, Rebeca Jesumary et al. Ser médico no PSF: formação acadêmica, perspectivas e trabalho cotidiano. Revista Brasileira de Educação Médica, Rio de Janeiro, v. 33, n. 3, p. 493-403, set. 2009.

KASTRUP, Virginia. 0 funcionamento da atenção no trabalho do cartógrafo. Psicologia e sociedade, Florianópolis, v. 19, n. 1, p. 15-23, jan. 2007.

LOURENÇO, Eloisio do Carmo et al. A inserção de equipes de saúde bucal no Programa Saúde da Família no Estado de Minas Gerais. Ciência \& Saúde Coletiva, Rio de Janeiro, v. 14, p. 1367-1377, set. 2009.

MACHADO, Maria Helena et al. Trabalhadores da saúde e sua trajetória na reforma sanitária. In: LIMA, Nísia Trindade et al. (Org.). Saúde e democracia: história e perspectivas do SUS. Rio de Janeiro: Fiocruz, 2005.

MERHY, Emerson Elias. Saúde: a cartografia do trabalho vivo. São Paulo: HUCITEC, 2002.

NOGUEIRA, Roberto Passos. Problemas de gestão e regulação do trabalho no SUS. Serviço Social e sociedade, São Paulo, v. 87, 2006.

NOGUEIRA, Roberto Passos; BARALDI, Solange; RODRIGUES, Valdemar de Almeida. Limites críticos das noções de precariedade e desprecarização do trabalho na administração pública. In: BARROS, André Falcão do Rego; SANTANA, José Paranaguá de; SANTOS NETO; Pedro Miguel (Org.). Observatório de recursos humanos no Brasil: estudos e análises. Brasília: Ministério da Saúde, 2004. v. 2.

PIERANTONI, Célia Regina; VARELLA, Tereza Cristina; FRANÇA, Tania. Recursos humanos e gestão do trabalho em saúde: da teoria para a prática. In: BARROS, André Falcão do Rego; SANTANA, José Paranaguá; SANTOS NETO; Pedro Miguel (Org.). Observatório de recursos humanos no Brasil: estudos e análises. Brasília: Ministério da Saúde, 2004. v. 2.

ROLNIK, Suely. Cartografia sentimental: transformações contemporâneas do desejo. Porto Alegre: Sulinas: Ed. UFRGS, 2006. 